\title{
Therapeutic targeting of ARID1A and PI3K/AKT pathway alterations in cholangiocarcinoma
}

\author{
Supharada Tessiri $^{1,2}$, Anchalee Techasen ${ }^{1,3}$, Sarinya Kongpetch ${ }^{3,4}$, Achira Namjan ${ }^{1,2}$, Watcharin Loilome $^{3,5}$, \\ Waraporn Chan-on $^{6}$, Raynoo Thanan ${ }^{5}$, Apinya Jusakul ${ }^{\text {Corresp. } 1,3}$ \\ ${ }^{1}$ Centre for Research and Development of Medical Diagnostic Laboratories, Faculty of Associated Medical Sciences, Khon Kaen University, Khon Kaen, \\ Thailand \\ 2 Biomedical Science Program, Graduate School, Khon Kaen University, Khon Kaen, Thailand \\ ${ }^{3}$ Cholangiocarcinoma Research Institute, Faculty of Medicine, Khon Kaen University, Khon Kaen, Thailand \\ 4 Department of Pharmacology, Faculty of Medicine, Khon Kaen University, Khon Kaen, Thailand \\ 5 Department of Biochemistry, Faculty of Medicine, Khon Kaen University, Khon Kaen, Thailand \\ ${ }^{6}$ Center for Research and Innovation, Faculty of Medical Technology, Mahidol University, Bangkok, Thailand \\ Corresponding Author: Apinya Jusakul \\ Email address: apinjus@kku.ac.th
}

Background: Genetic alterations in ARIDIA were detected at a high frequency in cholangiocarcinoma (CCA). Growing evidence indicates that the loss of ARID1A expression leads to activation of the PI3K/AKT pathway and increasing sensitivity of ARID1A-deficient cells for treatment with the PI3K/AKT inhibitor. Therefore, we investigated the association between genetic alterations of ARIDIA and the PI3K/AKT pathway and evaluated the effect of AKT inhibition on ARID1A-deficient CCA cells.

Methods: Alterations of ARIDIA, PI3K/AKT pathway-related genes, clinicopathological data and overall survival of 795 CCA patients were retrieved from cBio Cancer Genomics Portal (cBioPortal) databases. The association between genetic alterations and clinical data were analyzed. The effect of the AKT inhibitor (MK-2206) on ARID1A-deficient CCA cell lines and stable ARID1A-knockdown cell lines was investigated. Cell viability, apoptosis, and expression of AKT signaling were analyzed using an MTT assay, flow cytometry, and Western blots, respectively.

Results: The analysis of a total of 795 CCA samples revealed that ARIDIA alterations significantly cooccurred with mutations of EPHA2 ( $p<0.001)$, PIK3CA ( $p=0.047)$, and LAMA1 $(p=0.024)$. Among the EPHA2 mutant CCA tumors, $82 \%$ of EPHA2 mutant tumors co-occurred with ARID1A truncating mutations. CCA tumors with ARIDIA and EPHA2 mutations correlated with better survival compared to tumors with ARIDIA mutations alone. We detected that $30 \%$ of patients with PIK3CA driver missense mutations harbored ARIDIA-truncated mutations and $60 \%$ of LAMA1-mutated CCA co-occurred with truncating mutations of ARID1A. Interestingly, ARID1A-deficient CCA cell lines and ARID1A-knockdown CCA cells led to increased sensitivity to treatment with MK-2206 compared to the control. Treatment with MK-2206 induced apoptosis in ARID1A-knockdown KKU-213A and HUCCT1 cell lines and decreased the expression of $\mathrm{pAKT} \mathrm{T}^{\mathrm{S473}}$ and $\mathrm{mTOR}$.

Conclusion: These findings suggest a dependency of ARID1A-deficient CCA tumors with the activation of the PI3K/AKT-pathway, and that they may be more vulnerable to selective AKT pathway inhibitors which can be used therapeutically. 
1 Therapeutic Targeting of ARID1A and PI3K/AKT

2 Pathway Alterations in Cholangiocarcinoma

4 Supharada Tessiri ${ }^{1,2}$, Anchalee Techasen ${ }^{1,3}$, Sarinya Kongpetch ${ }^{3,4}$, Achira Namjan ${ }^{1,2}$, Watcharin

5 Loilome ${ }^{3,5}$, Waraporn Chan-on ${ }^{6}$, Raynoo Thanan ${ }^{5}$, Apinya Jusakul ${ }^{1,3}$

$7 \quad{ }^{1}$ Centre for Research and Development of Medical Diagnostic Laboratories, Faculty of

8 Associated Medical Sciences, Khon Kaen University, Khon Kaen, Thailand

9 2Biomedical Science Program, Graduate School, Khon Kaen University, Khon Kaen, Thailand

$10{ }^{3}$ Cholangiocarcinoma Research Institute, Faculty of Medicine, Khon Kaen University, Khon

11 Kaen, Thailand

$12{ }^{4}$ Department of Pharmacology, Faculty of Medicine, Khon Kaen University, Khon Kaen,

13 Thailand

$14{ }^{5}$ Department of Biochemistry, Faculty of Medicine, Khon Kaen University, Khon Kaen,

15 Thailand

$16{ }^{6}$ Center for Research and Innovation, Faculty of Medical Technology, Mahidol University,

17 Bangkok, Thailand

19 Corresponding Author:

20 Apinya Jusakul ${ }^{1,3}$

21 Department of Clinical Immunology and Transfusion Sciences, Faculty of Associated Medical

22 Sciences, 123 Mittraphap Road, Muang District, Khon Kaen, 40002, Thailand

23 Email address: apinjus@kku.ac.th 
24 Abstract

Background: Genetic alterations in ARIDIA were detected at a high frequency in cholangiocarcinoma (CCA). Growing evidence indicates that the loss of ARID1A expression leads to activation of the PI3K/AKT pathway and increasing sensitivity of ARID1A-deficient cells for treatment with the PI3K/AKT inhibitor. Therefore, we investigated the association between genetic alterations of $A R I D I A$ and the PI3K/AKT pathway and evaluated the effect of AKT inhibition on ARID1A-deficient CCA cells.

Methods: Alterations of ARIDIA, PI3K/AKT pathway-related genes and overall survival of 795 CCA patients were retrieved from cBio Cancer Genomics Portal (cBioPortal) databases. The association between genetic alterations and clinical data were analyzed. The effect of the AKT inhibitor (MK-2206) on ARID1A-deficient CCA cell lines and stable ARIDIA-knockdown cell lines was investigated. Cell viability, apoptosis, and expression of AKT signaling were analyzed using an MTT assay, flow cytometry, and Western blots, respectively.

Results: The analysis of a total of 795 CCA patients revealed that ARIDIA alterations significantly co-occurred with mutations of EPHA2 ( $p<0.001)$, PIK3CA ( $p=0.047)$, and LAMA1 ( $p=0.024$ ). Among the EPHA2 mutant CCA tumors, $82 \%$ of EPHA2 mutant tumors co-occurred with ARIDIA truncating mutations. CCA tumors with ARIDIA and EPHA2 mutations correlated with better survival compared to tumors with ARIDIA mutations alone. We detected that $30 \%$ of patients with PIK3CA driver missense mutations harbored ARIDIA-truncated mutations and $60 \%$ of LAMA1-mutated CCA co-occurred with truncating mutations of ARIDIA. Interestingly, ARID1A-deficient CCA cell lines and ARIDIA-knockdown CCA cells led to increased sensitivity to treatment with MK-2206 compared to the control. Treatment with MK-2206 induced apoptosis in ARIDIA-knockdown KKU-213A and HUCCT1 cell lines and decreased the expression of $\mathrm{pAKT}^{\mathrm{S} 473}$ and $\mathrm{mTOR}$.

Conclusion: These findings suggest a dependency of ARID1A-deficient CCA tumors with the activation of the PI3K/AKT pathway, and that they may be more vulnerable to selective AKT pathway inhibitors which can be used therapeutically. 
55

56

57

58

59

60

61

62

63

64

65

66

67

68

69

70

71

72

73

74

\section{Introduction}

Cholangiocarcinoma (CCA) is a malignancy arising from the epithelial cells along the biliary tree. The highest incidence rates of CCA have been reported in northeast Thailand, which is the endemic area of the group 1 carcinogen, the liver fluke, Opisthorchis viverrini (Ov) (Sripa \& Pairojkul, 2008; Alsaleh et al., 2018). Cholangiocarcinogenesis is induced via multifactorial mechanistic pathways. DNA damage and genetic alterations occur during CCA progression (Sripa et al., 2007, 2012). Although the best treatment option for localized CCA is curative surgical resection the five-year survival rate after surgical resection is low approximately $30 \%$ to 60\% (Meza-Junco et al., 2010; Patel, 2011). Thus, more treatment options for CCA patients are urgently needed. Growing evidence from molecular genetic studies of CCA has initiated a significant shift towards a precision medicine-based approach. In recent years, molecular targets with clinical significance include fibroblast growth factor receptor $(F G F R)$, isocitrate dehydrogenase $(I D H 1 / 2)$, human epidermal growth factor receptor $(H E R)$, neurotropic tyrosine kinase receptor (NTRK) fusions, and BRAF mutations have been identified in CCA tumors (Lamarca et al., 2020).

AT-rich interactive domain containing protein 1A (ARID1A or BAF250a) is a crucial non-catalytic subunit of human switch/sucrose nonfermentable (SWI/SNF) complex (Wu \& Roberts, 2013; Xu \& Tang, 2021). It plays an important role in crucial cellular processes including transcription, DNA replication, and DNA damage repair (Basu et al., 2016; BayonaFeliu et al., 2021). Of note, $A R I D 1 A$ is commonly inactivated in tumors including CCA. (Wu \& Roberts, 2013; Jusakul et al., 2017; Orlando et al., 2019). Silencing of ARID1A has resulted in a significant increase in proliferation in vitro (Samartzis et al., 2014). In CCA tumors, decreased expression of ARID1A was associated with CCA progression and metastasis, indicating the tumor-suppressor function of ARID1A in CCA (Chan-on et al., 2013; Namjan et al., 2020; Zhao et al., 2021). Recent studies have shown that ARID1A mutations is involved in carcinogenesis via activation of the phosphatidylinositol 3-kinase/protein kinase B (PI3K/AKT) pathway (Takeda et al., 2016). Co-occurrence of $A R I D I A$ alterations with PI3K/AKT pathway activation has been reported in ovarian clear cell carcinoma, breast cancer, and gastric cancer (Huang et al., 2014; Samartzis et al., 2014; Zhang et al., 2016; De \& Dey, 2019). Silencing of ARID1A in gastric, ovarian, glioma, and colon cancer cells has been shown to activate the phosphorylation of AKT, and PI3K (Zeng et al., 2013; Xie et al., 2014; Takeda et al., 2016; Zhang et al., 2016), suggesting 
86

87

88

89

90

91

92

93

94

95

96

97

98

an interrelationship between ARIDIA deficiency and PI3K/AKT pathway activation. Taken together, the crucial tumor suppressive roles of ARID1A shed light on targeted therapeutic strategies, hence there has been ongoing effort towards developing effective therapeutic strategies for ARIDIA deficient tumors (Bitler, Fatkhutdinov \& Zhang, 2015; Mathur, 2018; Mullen et al., 2021).

Interestingly, ARIDIA mutations and the depletion of ARID1A protein expression sensitized cancer cells to PI3K/AKT inhibitors. In breast and gastric cancer, ARIDIA-depleted cells showed an increased sensitivity to PI3K and AKT inhibitor compared to wild-type cells (Samartzis et al., 2014; Zhang et al., 2016; Yang et al., 2018b). This is of significant clinical importance since ARIDIA mutations or loss of the expression can be predictive of a favorable therapeutic response to inhibitors in the PI3K/AKT pathway. Although ARIDIA inactivation and PI3K/AKT pathway alteration frequently occur in CCA, the effect of PI3K or AKT inhibitor has not been well-defined in ARIDIA-deficient CCA. We therefore aimed to study the association between genetic alterations of ARIDIA and the PI3K/AKT pathway in CCA and investigate the effect of AKT inhibitor on ARIDIA-deficient CCA cell lines. This study will provide a unique opportunity for predicting favorable treatment responses to inhibitors of the PI3K/AKT pathway on ARIDIA-deficient CCA tumors which might further improve treatment outcome.

\section{Material and methods}

\section{Cell lines and cell culture}

The human cholangiocarcinoma cell lines KKU-452 (JCRB1772) (Saensa-ard et al., 2017), KKU-055 (JCRB1551), KKU-213A (JCRB1557) (Sripa et al., 2020), and KKU-100 (JCRB1568) (Sripa, 2005) were developed at Cholangiocarcinoma Research Institute, Khon Kaen University and deposited to the Japanese Cancer Research Resources Bank (JCRB, Ibaraki city, Osaka, Japan). The HUCCT1 (RCB1960) cell line was obtained from the RIKEN Bioresource Research Center (Ibaraki, Japan). The KKU-452, KKU-055, KKU-213A and KKU100 cell lines were cultured in Ham's F-12 whereas the HUCCT1 cells were cultured in RPMI containing $10 \%$ fetal bovine serum and penicillin/streptomycin $(100 \mathrm{U} / \mathrm{ml}$ and $100 \mu \mathrm{l} / \mathrm{ml})$. The cells were incubated in a humidified incubator at $37^{\circ} \mathrm{C}$ and $5 \% \mathrm{CO}_{2}$.

\section{Materials}

The following reagents and antibodies were used: MK-2206 (A-1909: Active Biochem, Hong Kong) was dissolved in DMSO at a concentration of $10 \mathrm{mM}$ as a stock solution, ARID1A 
117 (HPA005456: Sigma-Aldrich, Germany), phospho-AKT ${ }^{\mathrm{S} 473}$ (pAKT ${ }^{\mathrm{S} 473}$, SAB4300042: Sigma-

118 Aldrich, Germany), AKT (\#9272: Cell Signaling Technology, USA), mTOR (\#2983: Cell

119 Signaling Technology, USA), Bax (50599-2-Ig: Proteintech, USA), Bcl-2 (12789-1-AP:

120 Proteintech, USA), and $\beta$-actin (A5441: Sigma-Aldrich, Germany).

121 Analysis of gene alterations, using the open-access bio-database cBioPortal

122 We utilized the cBioPortal for Cancer Genomics (http://cbioportal.org), a web-based, open-

123 access resource for the analysis of cancer genomics data from The Cancer Genome Atlas

124 (TCGA) and The International Cancer Genome Consortium (ICGC). In the present study,

125 somatic mutations of $A R I D I A$, genes in RAS/PI3K/AKT pathways (mutation frequency $\geq 1.7 \%$

126 including: TP53, ARID1A, KRAS, EPHA2, STK11, PIK3CA, RASA1, LAMA2, ERBB2, LAMA1,

127 BRAF, ERBB4, FGFR2, PIK3R1, PTEN, KDR, NRAS, and TNN), clinicopathological data and

128 patient survival of 795 CCA patients/798 samples were analyzed. Collectively, the 6 data sets

129 included a TCGA data portal (Firehose Legacy) and a ICGC data portal (Jusakul et al., 2017;

130 Chan-on et al., 2013; Ong et al., 2012; Jiao et al., 2013; Lowery et al., 2018) (Table S1). We

131 utilized cBioPortal to analyze genetic alterations, co-occurrence, and mutual exclusivity in CCA

132 tumors. The OncoPrint, co-occurrence and mutual exclusivity of gene mutations were applied

133 according to the online instructions of the cBioPortal. The statistical test for detecting co-

134 occurrence and mutual exclusivity were based on a one-sided Fisher Exact Test, and Benjamini-

135 Hochberg FDR correction in 153 pairs of the 18 genes (Table S2).

136 Stable shRNA transduction

137 The cholangiocarcinoma cell lines were infected with MISSION® Lentiviral Transduction

138 Particles Clone containing specific short-hairpin RNA against ARID1A\#1 (SHCLNV-

139 NM_006015-TRCN0000059091, Sigma-Aldrich, Germany), ARID1A\#2 (SHCLNV-

140 NM_006015-TRCN0000059089, Sigma-Aldrich, Germany) and non-targeted shRNA

141 (SHC016V, Sigma-Aldrich, Germany) using polybrene (EMD Millipore, Sigma-Aldrich,

142 Germany). The following shRNA sequences were used: non-targeted shRNA: sense:

143 CCGGGCGCGATAGCGCTAATAATTTCTC, shARID1A\#1:

144 CCGTTGATGAACTCATTGGTT, and shARID1A\#2: GCCTGATCTATCTGGTTCAAT.

145 After 24-hours of infection, cells were selected using 1-2 $\mu \mathrm{g} / \mathrm{ml}$ of puromycin (Sigma-Aldrich,

146 Germany). Expression levels of ARID1A were confirmed by real time-PCR and Western blot.

147 Cell viability assay

Peer] reviewing PDF | (2021:08:64764:1:1:NEW 19 Nov 2021) 
148 Cell viability was determined by a methylthiazolyldiphenyl-tetrazolium bromide (MTT) assay

149 (PanReac Applichem, Germany). Cells were seeded into 96-well plates (Corning, NY, USA).

150 After 24-hour exposure of inhibitor, $100 \mu 1$ of $0.5 \mathrm{mg} / \mathrm{ml}$ MTT reagent was added and incubated

151 for 2 hours. After adding DMSO for 15 minutes, the absorbance was measured using a

152 microplate reader at a wavelength of $570 \mathrm{~nm}$. Each experiment was performed in triplicate and

153 the results were given as means \pm SD. The percentage of cell viability was calculated using the

154 formula: \% cell viability $=(\mathrm{Nt} / \mathrm{Nc}) \times 100$. $\mathrm{Nt}$ and $\mathrm{Nc}$ refer to the absorbance of the treated and

155 control groups, respectively.

156 Western blot

157 Cells were lysed in RIPA lysis buffer. Protein lysates were centrifuge at 14,000g for 20 mins at $1584^{\circ} \mathrm{C}$. Protein concentration was determined using the Pierce ${ }^{\mathrm{TM}}$ BCA Protein Assay Kit (Pierce 159 Biotechnology, USA). Protein lysates were resolved by SDS-PAGE and transferred onto PVDF 160 membranes. The membranes were blocked with 5\% skim milk or BSA in 1xTBS (1M Tris $\mathrm{HCl}$

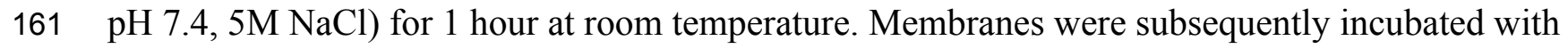
162 primary antibodies overnight at $4^{\circ} \mathrm{C}$. After washing, the secondary goat anti-Rabbit IgG-HRP 163 (G21234: Invitrogen, USA) or rabbit anti-Mouse IgG-HRP (A16166: Thermo Fisher Scientific, 164 USA) was used. The immunoreactive signals were visualized using Amersham ${ }^{\text {TM }}$ ECL $^{\text {TM }}$ Prime 165 Western Blotting Detection Reagent (GE Healthcare, UK).

166 Apoptosis assay

167 Cell apoptosis was detected using an Annexin V-FITC and propidium iodide (PI) Kit (V13241, 168 Invitrogen, USA) according to the manufacturer's protocol. Briefly, cells were seeded into 6169 well culture plates overnight. Cells were then exposed to MK-2206 at designated concentrations 170 and $0.3 \%$ DMSO was used as the control. After 24 hours, cells were trypsinized, washed with 171 ice-cold PBS, and resuspended in binding buffer containing Annexin V-FITC, whereupon, 172 Annexin V/PI was added. Cells were resuspended in reaction buffer containing PI and 173 immediately analyzed by BD FACSCanto II Flow cytometry (Becton Dickinson, USA) to detect 174 the rate of apoptosis.

175 RNA Extraction and Real Time-RT PCR

176 Total RNA was isolated from cell pellets using TRIzol® Reagent (Invitrogen, USA) according to 177 the manufacturer's protocol. Subsequently, $2 \mu \mathrm{g}$ of total RNA was converted to cDNA using 178 High-Capacity cDNA Reverse Transcription Kit (Applied Biosystems, USA). Real-time reverse 
179

180

181

182

183

184

185

186

187

188

189

190

191

192

193

194

195

196

197

198

199

200

201

202

203

204

205

206

207

208

209

transcription polymerase chain reaction (real time PCR) was performed using TaqMan gene expression assay: TaqMan probes (Hs00195664_ml ARID1A and hs99999903_m1 $\beta$-actin, ThermoFisher Scientific, USA) to detected mRNA levels of ARID1A and $\beta$-actin. Real time PCR was performed using the ABI real-time PCR system, Quantstudio ${ }^{\mathrm{TM}} 6$ Flex (Life technologies, Singapore). $\beta$-actin was used as the housekeeping gene.

\section{Statistical analysis}

All experiments were repeated at least two times. Data were expressed as the mean \pm standard deviation (SD). Statistical analysis was performed using SPSS 23.0 software (SPSS Inc., USA) or GraphPad Prism v.8.0 (GraphPad Inc., La Jolla, CA, USA) software. Overall survival (OS) curves were constructed according to the Kaplan-Meier estimator and differences between curves were tested for significance by means of log-rank tests. The half inhibitory concentration $\left(\mathrm{IC}_{50}\right)$ values were calculated by dose-response curves $\left(\mathrm{Y}=100 /\left(1+\mathrm{X} / \mathrm{IC}_{50}\right)\right)$. A two-tailed unpaired t-test was used for two-group comparisons. For multiple group comparisons, one-way analysis of variance, Kruskal-Wallis test, and Fisher's Least Significant Difference Test (LSD Test) test were used. A two-sided $p<0.05$ was considered statistically significant. Adjusted $p$ values were calculated using Benjamini-Hochberg correction.

\section{Results}

\section{ARID1A mutations and their co-occurrence with alterations in PI3K/AKT pathway}

To address if inactivation of $A R I D 1 A$ in CCA was associated with alterations of PI3K/AKT signaling, the mutations of $A R I D 1 A$ and genes in RAS/PI3K/AKT pathway were assessed using cBioPortal. A total of 795 CCA patients were included in the present study. Among kinaserelated genes, we selected 17 genes that were mutated (mutation frequency $\geq 1.7 \%$ ) in CCA (Fig. S1). Somatic mutations of ARIDIA were found in 19\% (137/711) of CCA patients. Truncating ARIDIA mutations were the most prevalent in ARIDIA mutated CCA (85\%, 116/137) (Figs. 1-2, Fig. 3A). The most common truncating ARID1A mutation observed in this cohort was frameshift deletion (G276Efs*87, G277Rfs*123 and M274Ifs*126, Fig. 2). Additionally, truncating ARIDIA mutations were more common in advanced stage (stage II (18\%, 20/112), III (13\%, 12/93) and IV (20\%, 31/153), Fig. 3C). Suggesting that ARIDIA mutation were predominantly in CCA with high tumor stage and may involve in CCA progression. We then investigated if $A R I D 1 A$ mutations co-occurred with mutations in the kinase-related pathway (Fig. S1). Interestingly, $A R I D 1 A$ mutations were significantly correlated with mutations of $E P H A 2$ 
210 (adjusted $p<0.001$ ), PIK3CA (adjusted $p=0.047$ ), and LAMA1 (adjusted $p=0.024)$ (Table S2).

211 EPHA2 was mutated in 9\% (46/516) of CCA patients (Fig. 1 and Figs. 3A-3B). Truncating

212 EPHA2 mutations were the most prevalent alterations in EPHA2 mutated CCA, particularly

213 frameshift deletion (P460Rfs*33) (Figs. 1-2, Fig. 3A). Among EPHA2 mutant CCA tumors, 48\%

214 (22/46) harbored ARIDIA mutations (Fig. 1, Fig. 3B). Of note, 82\% (18/22) of EPHA2 mutant

215 tumors co-occurred with $A R I D 1 A$ truncating mutations (Fig. 3B, Table S1). The frequency of

216 PIK3CA mutations was 6\% (41/711), and 80\% (33/41) of PIK3CA-mutated CCA tumors were

217 driver missense mutations (T1025A, E365K, E545K, E542K, C420R, Q546K, C901F, R38C,

218 N345K, R88Q, R108H, M1043I, K111E, H1047R and H1047L) (Figs. 1-2, Fig. 3A and Table

219 S1). We found that 37\% (15/41) of CCA with PIK3CA mutations harbored ARIDIA mutations.

220 Of note, 30\% (10/33) of CCA with PIK3CA driver missense mutations harbored ARIDIA-

221 truncated mutations (Fig. 3B, Table S1). LAMA1 was mutated in 4\% (20/516) of CCA (Fig. 1).

222 LAMA1 missense mutations were the most common mutations in CCA tumors (Fig. 2, Fig. 3A)

223 and 50\% (10/20) of LAMA1-mutated CCA co-occurring with ARIDIA mutations (Fig. 1, Fig.

224 3B). Interestingly, 60\% (6/10) of LAMA1-mutated CCA co-occurred with truncating mutations

225 of $A R I D 1 A$ (Fig. 3B, Table S1). We did not detect any significant correlation between mutations

226 in $A R I D I A$ and $K R A S, B R A F$, and $N R A S$. These results suggest interdependency between

227 ARIDIA mutations and alterations in the PI3K/AKT pathway, which may lead to activation of

228 the PI3K/AKT pathway (Fig. S1).

229 Coexistent $A R I D 1 A-E P H A 2$ mutations associated with shorter overall survival in CCA

230 patients

231 To examine the prognostic survival values of mutational co-occurrence between mutations of

232 ARIDIA, EPHA2, PIK3CA and LAMA1 in CCA, we further performed survival analysis in CCA

233 tumors with or without mutations of ARID1A, EPHA2, PIK3CA and LAMA1 (Table S1). As

234 shown in Figure 4A, there was no significant correlation between ARIDIA mutations and overall

235 survival ( $p=0.190, \log$-rank test), while co-occurrence of ARIDIA-EPHA2 mutations was

236 significantly correlated with poor overall survival ( $\mathrm{HR}=2.651 ; 95 \% \mathrm{CI}, 1.34-6.19 ; p<0.001, \log$ -

237 rank test, Fig. 4B). In addition, patients with ARID1A-EPHA2 mutations were found to have a

238 shorter overall survival compared to patients with $A R I D 1 A$ mutations (HR=1.905; 95\% CI, 0.92-

$2393.95 ; p=0.024$, log-rank test, Fig. 4C). In contrast, coexistent $A R I D 1 A-P I K 3 C A$ mutations and

240 ARIDIA-LAMA1 mutations was not significantly associated with shorter overall survival

Peer] reviewing PDF | (2021:08:64764:1:1:NEW 19 Nov 2021) 
$241(\mathrm{HR}=1.122 ; 95 \% \mathrm{CI}, 0.50-2.54 ; p=0.768$ and $\mathrm{HR}=0.598 ; 95 \% \mathrm{CI}, 0.25-1.66 ; p=0.371$,

242 respectively, log-rank test, Figs. 4D-4E). The insignificant shortening survival rate of the

243 ARIDIA-PIK3CA mutations and ARIDIA-LAMA1 mutations might be a result of limited power

244 of sample size ( $\mathrm{n}=9$ and $\mathrm{n}=6$, respectively).

245 Loss of ARID1A expression in CCA cell lines led to increased sensitivity towards the AKT246 inhibitor MK-2206

247 Several studies suggest the interdependency between loss of ARID1A protein expression and

$248 \mathrm{PI} 3 \mathrm{~K} / \mathrm{AKT}$ pathway activation which may also be more vulnerable to its inhibition (Samartzis et 249 al., 2014; Zhang et al., 2016; Lee et al., 2017). We previously demonstrated that CCA tumors

250 with $A R I D 1 A$ truncating mutations exhibited the loss or reduction of ARID1A protein expression 251 (Namjan et al., 2020). However, the effect of PI3K/AKT inhibitor has not been well-defined in 252 ARID1A-deficient CCA. The effect of MK-2206, however, has been investigated in early 253 clinical trials of biliary tract cancers (NCT01425879) (Ahn et al., 2015). We therefore evaluated 254 the effect of MK-2206 specifically in ARID1A-deficient CCA in vitro. To investigate sensitivity 255 to treatment with MK-2206, we examined the effect of MK-2206 on cell viability in CCA cell 256 lines. Among five CCA cell lines, KKU-213A, KKU-100 and HUCCT1 showed higher level of ARID1A protein expression compared to KKU-452 and KKU-055 cells (Figs. 5A-5B). Based on ARID1A protein expression, 4 CCA cell lines were selected as representative cells of ARID1Adepleted CCA cells (KKU-452 and KKU-055) and ARID1A-intact CCA cell lines (KKU-213A and KKU-100) for cell viability analysis. ARID1A-depleted CCA cells, KKU-452 and KKU-055 were found to be significantly more sensitive to treatment with MK-2206 (Fig. 5C). The $\mathrm{IC}_{50}$ values of KKU-452 and KKU-055 cells were $69 \pm 13 \mu \mathrm{M}$ and $85 \pm 6 \mu \mathrm{M}, 24$ hours, respectively, while the $\mathrm{IC}_{50}$ values of KKU-213A and KKU-100 cells were $152 \pm 17 \mu \mathrm{M}$, and $120 \pm 9 \mu \mathrm{M}, 24$ hours, respectively ( $p=0.016$, Kruskal-Wallis test, Fig. 5D and Table S3). These results show that ARID1A-deficient CCA cells are vulnerable to MK-2206.

To confirm the effect of MK-2206 in ARID1A-deficient CCA cells, ARID1A-knockdown KKU213A and HUCCT1 cell lines were used to investigate cell viability after the treatment with MK2206. ARID1A-knockdown KKU-213A and HUCCT1 cell lines were treated with 2.5-50 $\mu \mathrm{M}$ of the MK-2206, for 24, 48 and 72 hours, followed by cell viability detection. Decreased expression of ARID1A in ARID1A-knockdown cell lines was confirmed at mRNA and protein levels (Figs. 
272 6A-6B). ARID1A-knockdown KKU-213A and HUCCT1 cell lines showed higher sensitivity

273 towards treatment with MK-2206 when compared to the non-targeted shRNA control cells (Figs.

274 6C-6D). The $\mathrm{IC}_{50}$ values of $A R I D 1 A$-knockdown KKU-213A cells were significantly decreased

275 (shARID1A\#1 $=24 \pm 5 \mu \mathrm{M}$ and shARID1A\#2 $=24 \pm 7 \mu \mathrm{M}, 24$ hours, $p=0.016$, Fisher's LSD

276 test) when compared to the control ( $\mathrm{IC}_{50}=41 \pm 8 \mu \mathrm{M}, 24$ hours, Fig. 6E and Table S3).

277 Likewise, the $\mathrm{IC}_{50}$ values of $A R I D 1 A$-knockdown HUCCT1 cells significantly decreased

$278 \quad(\operatorname{shARID} 1 \mathrm{~A} \# 1=21 \pm 2 \mu \mathrm{M}$ and shARID1A\#2 $=19 \pm 2 \mu \mathrm{M}, 24$ hours, $p=0.027$ and 0.013,

279 respectively, Fisher's LSD test) when compared to the control $\left(\mathrm{IC}_{50}=33 \pm 8 \mu \mathrm{M}, 24\right.$ hours, Fig.

$2806 \mathrm{~F}$ and Table S3).

281 AKT inhibition induced apoptosis in $A R I D 1 A$-knockdown CCA cell lines and decreased 282 phosphorylation of AKT

283 We subsequently investigated whether inhibition of AKT leads to increased apoptosis in 284 ARID1A-knockdown cells. Treatment with MK-2206 at designated concentrations induced 285 apoptosis in ARID1A-knockdown KKU-213A cell lines (Figs. 7A-7B). Flow cytometry 286 confirmed that MK-2206 (30 $\mu \mathrm{M})$ significantly induced apoptosis in ARID1A-knockdown KKU287 213A cell lines compared to the control (68.2\% versus 44.9\%, respectively, $p=0.004)$. Even 288 though, ARIDIA-silencing in CCA cell lines minimally increased phosphorylation of AKT at 289 Ser-473 $\left(\mathrm{pAKT}^{\mathrm{S} 473}\right)$, treatment with MK-2206 $(30 \mu \mathrm{M})$ significantly reduced pAKT ${ }^{\mathrm{S} 473}$ level in 290 ARIDIA-knockdown KKU-213A and HUCCT-1 cell lines compared to the non-targeting control 291 shRNA (Figs. 8A-8C). Notably, pAKT ${ }^{\mathrm{S} 473}$ levels were significantly reduced in ARIDIA-

292 knockdown KKU-213A and HUCCT1 cell lines after the treatment with MK-2206 compared to 293 control shRNA (Fig. 8C). Likewise, treatment with MK-2206 reduced mTOR protein expression 294 in ARIDIA-knockdown KKU-213A and HUCCT1 cells compared to the non-targeting control 295 shRNA (Fig. 8D). Consistently, MK-2206 induced apoptosis in ARID1A-knockdown cell lines 296 through the increasing of the Bax/Bcl-2 ratio (Figs. 8A-8B and Fig. S2).

\section{Discussion}

298 CCA is an aggressive malignancy having increased incidence globally with a high mortality rate 299 (Banales et al., 2020). Most CCA patients are diagnosed in the advanced metastatic stage of the 300 disease, resulting in poor survival and poor outcome of the local and systemic therapies (Banales 301 et al., 2020). Recent comprehensive genomic profiling of CCA has revealed potential molecular 302 targets and opened new horizons for tailored treatment for CCA. Among the chromatin 
303

304

305

306

307

308

309

310

311

312

313

314

315

316

317

318

319

320

321

322

323

324

325

326

327

328

329

330

331

332

333

remodeling genes, $A R I D 1 A$ shows one of the highest mutation rates across different cancer types in people, and it is one of the most frequently inactivated genes in CCA (Chan-on et al., 2013; Jusakul et al., 2017). Many reports suggest that ARID1A plays a tumor suppressive role in various cancers. These findings have increased interest in developing targeted therapies that take advantage of $A R I D 1 A$ mutations. Interestingly, $A R I D 1 A$ alterations often co-exist with genetic alterations that lead to activation of the PI3K/AKT pathway (Bitler, Fatkhutdinov \& Zhang, 2015). There is evidence indicating that $A R I D I A$-mutated cancers may also be vulnerable to therapeutic intervention by targeting the PI3K/AKT pathway (Samartzis et al., 2014). Although, ARIDIA inactivation and alterations of the PI3K/AKT pathway frequently occur in CCA, the synthetic lethality by targeting the PI3K/AKT pathway in ARIDIA-deficient CCA has not been studied. Herein, we demonstrated ARIDIA mutations and its co-occurrence with alterations of the PI3K/AKT pathway in CCA. To the best of our knowledge, this is the first time that a synthetic lethality has been shown between ARID1A deficiency and the inhibition of the PI3K/AKT pathway in vitro of CCA. Furthermore, we found that depletion of ARID1A considerably increased sensitivity toward AKT inhibition in CCA cell lines.

Firstly, we investigated the association between ARIDIA mutations and activation of $\mathrm{PI} 3 \mathrm{~K} / \mathrm{AKT}$ pathway. The PI3K/AKT pathway activation could be a result of receptor tyrosine kinases activation or somatic mutations in specific components of the signaling pathway such as PTEN, PIK3CA, and AKT isoforms (Shukla \& Mukherjee, 2018). We explored gene alterations of $A R I D 1 A$ and genes in PI3K/AKT pathway in 6 studies using the online resource cBioPortal Web. Our results indicated that ARIDIA mutations were associated with somatic mutations of EPHA2, PIK3CA, and LAMA1. EPHA2, a member of the tyrosine kinase family, has been found to be frequently mutated in intrahepatic CCA (ICC). Of note, in vitro and in vivo experiments revealed that EPHA2 mutations led to ligand-independent phosphorylation of $\operatorname{Ser}^{897}$ and were associated with lymph node metastasis of ICC (Sheng et al., 2019). Additionally, ARIDIA and EPHA2 mutations were associated with lymph node metastasis of ICC (Sheng et al., 2019). In the present study, we found $82 \%(18 / 22)$ of EPHA2 mutant tumors co-occurred with ARIDIA truncating mutations, suggesting an interdependency of ARID1A and EPHA2 pathways. Interestingly, patients with ARIDIA-EPHA2 mutations were found to have a shorter overall survival than patients without $A R I D 1 A$ mutations. Additionally, we also found coexistent of ARIDIA-PIK3CA mutations in this cohort. Coexistent ARIDIA-PIK3CA mutations promotes 
334 tumorigenesis has been shown in several types of cancer (Chandler et al., 2015; Takeda et al., 335 2016; Wilson et al., 2019). PIK3CA mutations lead to dysregulation of the PI3K/AKT pathway 336 (Arcaro \& Guerreiro, 2007). Moreover, the H1047R/L PIK3CA mutations exhibited increased 337 kinase activation and resulted in increased sensitivity to the ATP-competitive inhibitor (Mankoo, 338 Sukumar \& Karchin, 2009). Combination of inactivation of $A R I D 1 A$ with activation of PIK3CA 339 activates the development of ovarian endometrioid carcinoma (Wilson et al., 2019). In ovarian 340 clear-cell carcinomas, $40 \%$ of tumors harbor PIK3CA somatic mutations and the majority of 341 these were ARIDIA-deficient tumors (Yamamoto et al., 2012). Here, we found 30\% (10/33) of 342 CCA with PIK3CA driver missense (E545K, H1047L, R88Q, R108H, M1043I, and K111E) 343 mutations harbored $A R I D I A$-truncated mutations. This evidence suggests a synergistic mode of 344 ARID1A mutations and PIK3CA activation, which resulted in the activation of the PI3K/AKT 345 pathway. Importantly, our results have shown for the first time the association between 346 mutations in ARIDIA and LAMA1. LAMA1 is a subunit of laminins family. Laminins are the 347 main component of the basement membrane, and they can promote tumor growth and metastasis 348 (Patarroyo, Tryggvason \& Virtanen, 2002; Engbring \& Kleinman, 2003). In clear cell renal cell carcinoma, LAMA1 is one of the markers associated with early metastatic cancer (Yang et al., 2017). We have shown that $60 \%$ (6/10) of LAMA1-mutated CCA co-occurred with truncating mutations of $A R I D 1 A$. Hence, tumors with ARIDIA deficiency may depend more on the activation of the PI3K/AKT pathway.

Currently, molecular therapies targeting the PI3K/AKT signaling pathway are under investigation in a clinical trial for several malignancies (NCT01307631 and NCT01277757). The effectiveness of AKT inhibitor (MK-2206) in inducing apoptosis was reported as a monotherapy in CCA cell lines in vitro (Wilson et al., 2015). A phase II clinical trial also evaluated the efficacy of MK-2206 on biliary tract cancers (NCT01425879). However, the clinical efficacy has been limited, to date, possibly because of the lack of appropriate patient selection based on a reliable biomarker(s). Interestingly, $A R I D 1 A$-deficient cancers are more sensitive to PI3K/AKT inhibitors (Samartzis et al., 2014; Takeda et al., 2016; Zhang et al., 2016; Lee et al., 2017). Here, we demonstrated that $A R I D I A$-deficient CCA cells show increased sensitivity to treatment with AKT inhibitor in vitro. Samartzis et al. (2014) have indicated that ARIDIA-deficient breast carcinoma cell lines and human primary lung fibroblasts increased sensitivity to AKT-inhibitors MK-2206, perifosine and PI3K-inhibitor buparlisib (Samartzis et al., 2014). Moreover, Yang et 
365

366

367

368

369

370

371

372

373

374

375

376

377

378

379

380

381

382

383

384

385

386

387

388

389

390

391

392

393

394

al. (2018) showed that PI3K/AKT inhibitors (LY294002 and MK-2206) could alleviate radioresistance through the induction of apoptosis and weakening DNA damage repair in ARIDIA mutant pancreatic cancer cells (Yang et al., 2018a). Lee et al. (2017) showed that ARID1A-deficient gastric cell lines were more vulnerable to AKT inhibitor GSK690693 (Lee et al., 2017). Likewise, we have shown that MK-2206 targeted $\mathrm{pAKT}^{\mathrm{S} 473}$ downregulated CCA cell proliferation and induced apoptosis, conferred by ARID1A depletion. This suggests a synthetic lethal interaction between loss of ARID1A and inhibition of the PI3K/AKT pathway. In contrast to ovarian clear cell and endometrioid carcinomas (Samartzis et al., 2014), the effect of ARIDIA knockdown on AKT inhibition was relatively small in CCA in vitro which could be a result of weak activation of $\mathrm{AKT}$ after $A R I D 1 A$ knockdown. Additionally, the $\mathrm{IC}_{50}$ values reported in this study were higher than those other in vitro models (Samartzis et al., 2014; Lee et al., 2017; Ewald et al., 2013; Wilson et al., 2015). A previous study demonstrated that the antiproliferative and AKT inhibition effects of MK-2206 were varied among cell lines with different genetic background (Hirai et al., 2010), suggesting that other mechanisms responsible for the synthetic lethality of ARID1A inactivation and AKT inhibition remain to be elucidated.

There were some limitations in our study. Although our data provide in silico information regarding the association between $A R I D 1 A$ mutations and PI3K/AKT pathway, its exact mechanism and function in human cancer cells has yet to be fully elucidated. We also acknowledge that a limitation of our study is the lack of in vivo experiments. Future work should investigate MK-2206 properties in vivo and center on developing more effective combination therapies to improve treatment efficacy. Further assessment of the mechanism of action could shed light on the clinical utility of using AKT inhibitors to treat CCA patients harboring ARIDIA alterations.

\section{Conclusions}

Our results have demonstrated that depletion of ARID1A leads to a significantly increased sensitivity towards AKT-inhibition in CCA cells in vitro. Additionally, our results have shown the co-occurrence of genetic alterations of $A R I D 1 A$ with the PI3K/AKT pathway in CCA tumors. The findings suggest a synthetic lethal interaction between the loss of ARID1A and the inhibition of the PI3K/AKT pathway. Furthermore, results from our study provide a sound basis and a unique opportunity for predicting favorable treatment responses to small molecule 
395 396 397 398 399 400 401 402 403 404 405 406 407 408 409 410 411 412 413 414 415 416

inhibitors of the PI3K/AKT pathway on $A R I D 1 A$-mutated CCA which can improve treatment outcomes.

\section{Acknowledgments}

We would like to thank the patients and Cholangiocarcinoma Research Institute, Khon Kaen University, Thailand. We would like to acknowledge Professor Ross Hector Andrews, for editing the manuscript via Publication Clinic KKU, Thailand.

\section{References}

Ahn DH, Li J, Wei L, Doyle A, Marshall JL, Schaaf LJ, Phelps MA, Villalona-Calero MA, Bekaii-Saab T. 2015. Results of an abbreviated phase-II study with the Akt Inhibitor MK-2206 in Patients with Advanced Biliary Cancer. Scientific Reports 5:12122. DOI: $10.1038 /$ srep 12122 .

Alsaleh M, Leftley Z, Barbera TA, Sithithaworn P, Khuntikeo N, Loilome W, Yongvanit P, Cox IJ, Chamodol N, Syms RRA, Andrews RH, Taylor-Robinson SD. 2018. Cholangiocarcinoma: a guide for the nonspecialist. International Journal of General Medicine 12:13-23. DOI: 10.2147/IJGM.S186854.

Arcaro A, Guerreiro AS. 2007. The Phosphoinositide 3-Kinase Pathway in Human Cancer: Genetic Alterations and Therapeutic Implications. Current Genomics 8:271-306. DOI: $10.2174 / 138920207782446160$.

Banales JM, Marin JJG, Lamarca A, Rodrigues PM, Khan SA, Roberts LR, Cardinale V, Carpino G, Andersen JB, Braconi C, Calvisi DF, Perugorria MJ, Fabris L, Boulter L, Macias RIR, Gaudio E, Alvaro D, Gradilone SA, Strazzabosco M, Marzioni M, Coulouarn C, Fouassier L, Raggi C, Invernizzi P, Mertens JC, Moncsek A, Rizvi S, Heimbach J, Koerkamp BG, Bruix J, Forner A, Bridgewater J, Valle JW, Gores GJ. 2020. Cholangiocarcinoma 2020: the next horizon in mechanisms and management. Nature Reviews Gastroenterology \& Hepatology 17:557-588. DOI: 10.1038/s41575-020-0310-z.

Basu GD, White T, LoBello J, Lau K, Syring ML, Krishnan S, Gonzalez-Malerva L, Royce T, Kurdoglu A, Halbert M, Kiefer J, Cherni I, Aldrich J, Izatt T, Russell M, Nasser S, Carpten JD, Craig DW, Demeure MJ. 2016. ARID1A Alterations in Gastrointestinal Cancers and Therapeutic Opportunities. Journal of Clinical Oncology 34:671. 
424 Bayona-Feliu A, Barroso S, Muñoz S, Aguilera A. 2021. The SWI/SNF chromatin remodeling

425

426

427

428

429

430

431

432

433

434

435

436

437

438

439

440

441

442

443

444

445

446

447

448

449

450

451

452

453

454 complex helps resolve R-loop-mediated transcription-replication conflicts. Nature Genetics 53:1050-1063. DOI: 10.1038/s41588-021-00867-2.

Bitler BG, Fatkhutdinov N, Zhang R. 2015. Potential Therapeutic Targets in ARID1A-Mutated Cancers. Expert Opinion on Therapeutic Targets 19:1419-1422. DOI: 10.1517/14728222.2015.1062879.

Chandler RL, Damrauer JS, Raab JR, Schisler JC, Wilkerson MD, Didion JP, Starmer J, Serber D, Yee D, Xiong J, Darr DB, de Villena FP-M, Kim WY, Magnuson T. 2015. Coexistent ARID1A-PIK3CA mutations promote ovarian clear-cell tumorigenesis through protumorigenic inflammatory cytokine signalling. Nature Communications 6:6118. DOI: 10.1038/ncomms7118.

Chan-on W, Nairismägi M-L, Ong CK, Lim WK, Dima S, Pairojkul C, Lim KH, McPherson JR, Cutcutache I, Heng HL, Ooi L, Chung A, Chow P, Cheow PC, Lee SY, Choo SP, Tan IBH, Duda D, Nastase A, Myint SS, Wong BH, Gan A, Rajasegaran V, Ng CCY, Nagarajan S, Jusakul A, Zhang S, Vohra P, Yu W, Huang D, Sithithaworn P, Yongvanit P, Wongkham S, Khuntikeo N, Bhudhisawasdi V, Popescu I, Rozen SG, Tan P, Teh BT. 2013. Exome sequencing identifies distinct mutational patterns in liver fluke-related and non-infection-related bile duct cancers. Nature Genetics 45:1474-1478. DOI: 10.1038/ng.2806.

De P, Dey N. 2019. Mutation-Driven Signals of ARID1A and PI3K Pathways in Ovarian Carcinomas: Alteration Is An Opportunity. International Journal of Molecular Sciences 20:5732. DOI: 10.3390/ijms20225732.

Engbring JA, Kleinman HK. 2003. The basement membrane matrix in malignancy: ECM in malignancy. The Journal of Pathology 200:465-470. DOI: 10.1002/path.1396.

Ewald F, Grabinski N, Grottke A, Windhorst S, Nörz D, Carstensen L, Staufer K, Hofmann BT, Diehl F, David K, Schumacher U, Nashan B, Jücker M. 2013. Combined targeting of AKT and mTOR using MK-2206 and RAD001 is synergistic in the treatment of cholangiocarcinoma. International Journal of Cancer 133:2065-2076. DOI: 10.1002/ijc.28214.

Hirai H, Sootome H, Nakatsuru Y, Miyama K, Taguchi S, Tsujioka K, Ueno Y, Hatch H, Majumder PK, Pan B-S, Kotani H. 2010. MK-2206, an Allosteric Akt Inhibitor, 
455

456

457

458

459

460

461

462

463

464

465

466

467

468

469

470

471

472

473

474

475

476

477

478

479

480

481

482

483

484

485

Enhances Antitumor Efficacy by Standard Chemotherapeutic Agents or Molecular Targeted Drugs In vitro and In vivo. Molecular Cancer Therapeutics 9:1956-1967. DOI: 10.1158/1535-7163.MCT-09-1012.

Huang H-N, Lin M-C, Huang W-C, Chiang Y-C, Kuo K-T. 2014. Loss of ARID1A expression and its relationship with PI3K-Akt pathway alterations and ZNF217 amplification in ovarian clear cell carcinoma. Modern Pathology 27:983-990. DOI: 10.1038/modpathol.2013.216.

Jiao Y, Pawlik TM, Anders RA, Selaru FM, Streppel MM, Lucas DJ, Niknafs N, Guthrie VB, Maitra A, Argani P, Offerhaus GJA, Roa JC, Roberts LR, Gores GJ, Popescu I, Alexandrescu ST, Dima S, Fassan M, Simbolo M, Mafficini A, Capelli P, Lawlor RT, Ruzzenente A, Guglielmi A, Tortora G, de Braud F, Scarpa A, Jarnagin W, Klimstra D, Karchin R, Velculescu VE, Hruban RH, Vogelstein B, Kinzler KW, Papadopoulos N, Wood LD. 2013. Exome sequencing identifies frequent inactivating mutations in BAP1, ARID1A and PBRM1 in intrahepatic cholangiocarcinomas. Nature Genetics 45:14701473. DOI: $10.1038 / \mathrm{ng} .2813$.

Jusakul A, Cutcutache I, Yong CH, Lim JQ, Huang MN, Padmanabhan N, Nellore V, Kongpetch S, Ng AWT, Ng LM, Choo SP, Myint SS, Thanan R, Nagarajan S, Lim WK, Ng CCY, Boot A, Liu M, Ong CK, Rajasegaran V, Lie S, Lim AST, Lim TH, Tan J, Loh JL, McPherson JR, Khuntikeo N, Bhudhisawasdi V, Yongvanit P, Wongkham S, Totoki Y, Nakamura H, Arai Y, Yamasaki S, Chow PK-H, Chung AYF, Ooi LLPJ, Lim KH, Dima S, Duda DG, Popescu I, Broet P, Hsieh S-Y, Yu M-C, Scarpa A, Lai J, Luo D-X, Carvalho AL, Vettore AL, Rhee H, Park YN, Alexandrov LB, Gordân R, Rozen SG, Shibata T, Pairojkul C, Teh BT, Tan P. 2017. Whole-Genome and Epigenomic Landscapes of Etiologically Distinct Subtypes of Cholangiocarcinoma. Cancer Discovery 7:1116-1135. DOI: 10.1158/2159-8290.CD-17-0368.

Lee D, Yu EJ, Ham I-H, Hur H, Kim Y-S. 2017. AKT inhibition is an effective treatment strategy in ARID1A-deficient gastric cancer cells. OncoTargets and Therapy 10:41534159. DOI: $10.2147 /$ OTT.S139664.

Lowery MA, Ptashkin R, Jordan E, Berger MF, Zehir A, Capanu M, Kemeny NE, O'Reilly EM, El-Dika I, Jarnagin WR, Harding JJ, D’Angelica MI, Cercek A, Hechtman JF, Solit DB, Schultz N, Hyman DM, Klimstra DS, Saltz LB, Abou-Alfa GK. 2018. Comprehensive 
486

487

488

489

490

491

492

493

494

495

496

497

498

499

500

501

502

503

504

505

506

507

508

509

510

511

512

513

514

515

516

Molecular Profiling of Intrahepatic and Extrahepatic Cholangiocarcinomas: Potential Targets for Intervention. Clinical Cancer Research 24:4154-4161. DOI: 10.1158/10780432.CCR-18-0078.

Mankoo PK, Sukumar S, Karchin R. 2009. PIK3CA somatic mutations in breast cancer: Mechanistic insights from Langevin dynamics simulations. Proteins: Structure, Function, and Bioinformatics 75:499-508. DOI: 10.1002/prot.22265.

Mathur R. 2018. ARID1A loss in cancer: Towards a mechanistic understanding. Pharmacology \& Therapeutics 190:15-23. DOI: 10.1016/j.pharmthera.2018.05.001.

Meza-Junco J, Montano-Loza AJ, Ma M, Wong W, Sawyer MB, Bain VG. 2010. Cholangiocarcinoma: Has There been Any Progress? Canadian Journal of Gastroenterology 24:52-57. DOI: 10.1155/2010/704759.

Namjan A, Techasen A, Loilome W, Sa-ngaimwibool P, Jusakul A. 2020. ARID1A alterations and their clinical significance in cholangiocarcinoma. PeerJ 8:e10464. DOI: 10.7717/peerj.10464.

Ong CK, Subimerb C, Pairojkul C, Wongkham S, Cutcutache I, Yu W, McPherson JR, Allen GE, Ng CCY, Wong BH, Myint SS, Rajasegaran V, Heng HL, Gan A, Zang ZJ, Wu Y, Wu J, Lee MH, Huang D, Ong P, Chan-on W, Cao Y, Qian C-N, Lim KH, Ooi A, Dykema K, Furge K, Kukongviriyapan V, Sripa B, Wongkham C, Yongvanit P, Futreal PA, Bhudhisawasdi V, Rozen S, Tan P, Teh BT. 2012. Exome sequencing of liver flukeassociated cholangiocarcinoma. Nature Genetics 44:690-693. DOI: 10.1038/ng.2273.

Orlando KA, Nguyen V, Raab JR, Walhart T, Weissman BE. 2019. Remodeling the cancer epigenome: mutations in the SWI/SNF complex offer new therapeutic opportunities. Expert Review of Anticancer Therapy 19:375-391. DOI: 10.1080/14737140.2019.1605905.

Patarroyo M, Tryggvason K, Virtanen I. 2002. Laminin isoforms in tumor invasion, angiogenesis and metastasis. Seminars in Cancer Biology 12:197-207. DOI: 10.1016/S1044579X(02)00023-8.

Patel T. 2011. Cholangiocarcinoma - controversies and challenges. Nature Reviews Gastroenterology \& Hepatology 8:189-200. DOI: 10.1038/nrgastro.2011.20.

Saensa-ard S, Leuangwattanawanit S, Senggunprai L, Namwat N, Kongpetch S, Chamgramol Y, Loilome W, Khansaard W, Jusakul A, Prawan A, Pairojkul C, Khantikeo N, Yongvanit P, 
517

518

519

520

521

522

523

524

525

526

527

528

529

530

531

532

533

534

535

536

537

538

539

540

541

542

543

544

545

546

547

Kukongviriyapan V. 2017. Establishment of cholangiocarcinoma cell lines from patients in the endemic area of liver fluke infection in Thailand. Tumor Biology 39:1010428317725925. DOI: 10.1177/1010428317725925.

Samartzis EP, Gutsche K, Dedes KJ, Fink D, Stucki M, Imesch P. 2014. Loss of ARID1A expression sensitizes cancer cells to PI3K- and AKT-inhibition. Oncotarget 5:52955303. DOI: 10.18632/oncotarget.2092.

Sheng Y, Wei J, Zhang Y, Gao X, Wang Z, Yang J, Yan S, Zhu Y, Zhang Z, Xu D, Wang C, Zheng Y, Dong Q, Qin L. 2019. Mutated EPHA2 is a target for combating lymphatic metastasis in intrahepatic cholangiocarcinoma. International Journal of Cancer 144:2440-2452. DOI: 10.1002/ijc.31979.

Shukla P, Mukherjee S. 2018. Role of chromatin remodeling protein, ARID1A and emerging therapies in ARID1A mutated ovarian and endometrial cancer. The research reports 2:e1-11.

Sripa B. 2005. Establishment and characterization of an opisthorchiasis-associated cholangiocarcinoma cell line (KKU-100). World Journal of Gastroenterology 11:3392. DOI: 10.3748/wjg.v11.i22.3392.

Sripa B, Brindley PJ, Mulvenna J, Laha T, Smout MJ, Mairiang E, Bethony JM, Loukas A. 2012. The tumorigenic liver fluke Opisthorchis viverrini - multiple pathways to cancer. Trends in Parasitology 28:395-407. DOI: 10.1016/j.pt.2012.07.006.

Sripa B, Kaewkes S, Sithithaworn P, Mairiang E, Laha T, Smout M, Pairojkul C, Bhudhisawasdi V, Tesana S, Thinkamrop B, Bethony JM, Loukas A, Brindley PJ. 2007. Liver Fluke Induces Cholangiocarcinoma. PLoS Medicine 4:e201. DOI: 10.1371/journal.pmed.0040201.

Sripa B, Pairojkul C. 2008. Cholangiocarcinoma: lessons from Thailand: Current Opinion in Gastroenterology 24:349-356. DOI: 10.1097/MOG.0b013e3282fbf9b3.

Sripa B, Seubwai W, Vaeteewoottacharn K, Sawanyawisuth K, Silsirivanit A, Kaewkong W, Muisuk K, Dana P, Phoomak C, Lert-itthiporn W, Luvira V, Pairojkul C, Teh BT, Wongkham S, Okada S, Chamgramol Y. 2020. Functional and genetic characterization of three cell lines derived from a single tumor of an Opisthorchis viverrini-associated cholangiocarcinoma patient. Human Cell 33:695-708. DOI: 10.1007/s13577-020-00334W. 
548 Takeda T, Banno K, Okawa R, Yanokura M, Iijima M, Irie-Kunitomi H, Nakamura K, Iida M, 549 Adachi M, Umene K, Nogami Y, Masuda K, Kobayashi Y, Tominaga E, Aoki D. 2016.

550

551

552

553

554

555

556

557

558

559

560

561

562

563

564

565

566

567

568

569

570

571

572

573

574

575

576

577

578

ARID1A gene mutation in ovarian and endometrial cancers (Review). Oncology Reports 35:607-613. DOI: 10.3892/or.2015.4421.

Wilson JM, Kunnimalaiyaan S, Kunnimalaiyaan M, Gamblin T. 2015. Inhibition of the AKT pathway in cholangiocarcinoma by MK2206 reduces cellular viability via induction of apoptosis. Cancer Cell International 15:13. DOI: 10.1186/s12935-015-0161-9.

Wilson MR, Reske JJ, Holladay J, Wilber GE, Rhodes M, Koeman J, Adams M, Johnson B, Su R-W, Joshi NR, Patterson AL, Shen H, Leach RE, Teixeira JM, Fazleabas AT, Chandler RL. 2019. ARID1A and PI3-kinase pathway mutations in the endometrium drive epithelial transdifferentiation and collective invasion. Nature Communications 10:3554. DOI: $10.1038 / \mathrm{s} 41467-019-11403-6$.

Wu JN, Roberts CWM. 2013. ARID1A Mutations in Cancer: Another Epigenetic Tumor Suppressor? Cancer Discovery 3:35-43. DOI: 10.1158/2159-8290.CD-12-0361.

Xie C, Fu L, Han Y, Li Q, Wang E. 2014. Decreased ARID1A expression facilitates cell proliferation and inhibits 5-fluorouracil-induced apoptosis in colorectal carcinoma. Tumor Biology 35:7921-7927. DOI: 10.1007/s13277-014-2074-y.

$\mathrm{Xu}$ S, Tang C. 2021. The Role of ARID1A in Tumors: Tumor Initiation or Tumor Suppression? Frontiers in Oncology 11:3891. DOI: 10.3389/fonc.2021.745187.

Yamamoto S, Tsuda H, Takano M, Tamai S, Matsubara O. 2012. Loss of ARID1A protein expression occurs as an early event in ovarian clear-cell carcinoma development and frequently coexists with PIK3CA mutations. Modern Pathology 25:615-624. DOI: 10.1038/modpathol.2011.189.

Yang H, Huo P, Hu G, Wei B, Kong D, Li H. 2017. Identification of gene markers associated with metastasis in clear cell renal cell carcinoma. Oncology Letters 13:4755-4761. DOI: 10.3892/ol.2017.6084.

Yang L, Yang G, Ding Y, Dai Y, Xu S, Guo Q, Xie A, Hu G. 2018a. Inhibition of PI3K/AKT Signaling Pathway Radiosensitizes Pancreatic Cancer Cells with ARID1A Deficiency in Vitro. Journal of Cancer 9:890-900. DOI: 10.7150/jca.21306.

Yang L, Yang G, Ding Y, Huang Y, Liu S, Zhou L, Wei W, Wang J, Hu G. 2018b. Combined treatment with PI3K inhibitor BKM120 and PARP inhibitor olaparib is effective in

Peer] reviewing PDF | (2021:08:64764:1:1:NEW 19 Nov 2021) 
579 inhibiting the gastric cancer cells with ARID1A deficiency. Oncology Reports. DOI: $580 \quad 10.3892 /$ or.2018.6445.

581 Zeng Y, Liu Z, Yang J, Liu Y, Huo L, Li Z, Lan S, Wu J, Chen X, Yang K, Li C, Li M, Liu J. 582 2013. ARID1A is a tumour suppressor and inhibits glioma cell proliferation via the PI3K 583 pathway. Head \& Neck Oncology 5:6.

584 Zhang Q, Yan H-B, Wang J, Cui S-J, Wang X-Q, Jiang Y-H, Feng L, Yang P-Y, Liu F. 2016. 585 Chromatin remodeling gene AT-rich interactive domain-containing protein $1 \mathrm{~A}$ 586 suppresses gastric cancer cell proliferation by targeting PIK3CA and PDK1. Oncotarget $587 \quad 7: 46127-46141$. DOI: 10.18632/oncotarget.10060.

588 Zhao S, Xu Y, Wu W, Wang P, Wang Y, Jiang H, Zhu J. 2021. ARID1A Variations in 589 Cholangiocarcinoma: Clinical Significances and Molecular Mechanisms. Frontiers in 590 Oncology 11:693295. DOI: 10.3389/fonc.2021.693295.

591 
Figure 1

Genetic alterations of the ARIDIA mutations with alterations of EPHA2, PIK3CA and LAMA1.

The Oncoplot shows a co-occurrence pattern of ARID1A mutations with EPHA2, PIK3CA and LAMA1 genes in 795 CCA patients.

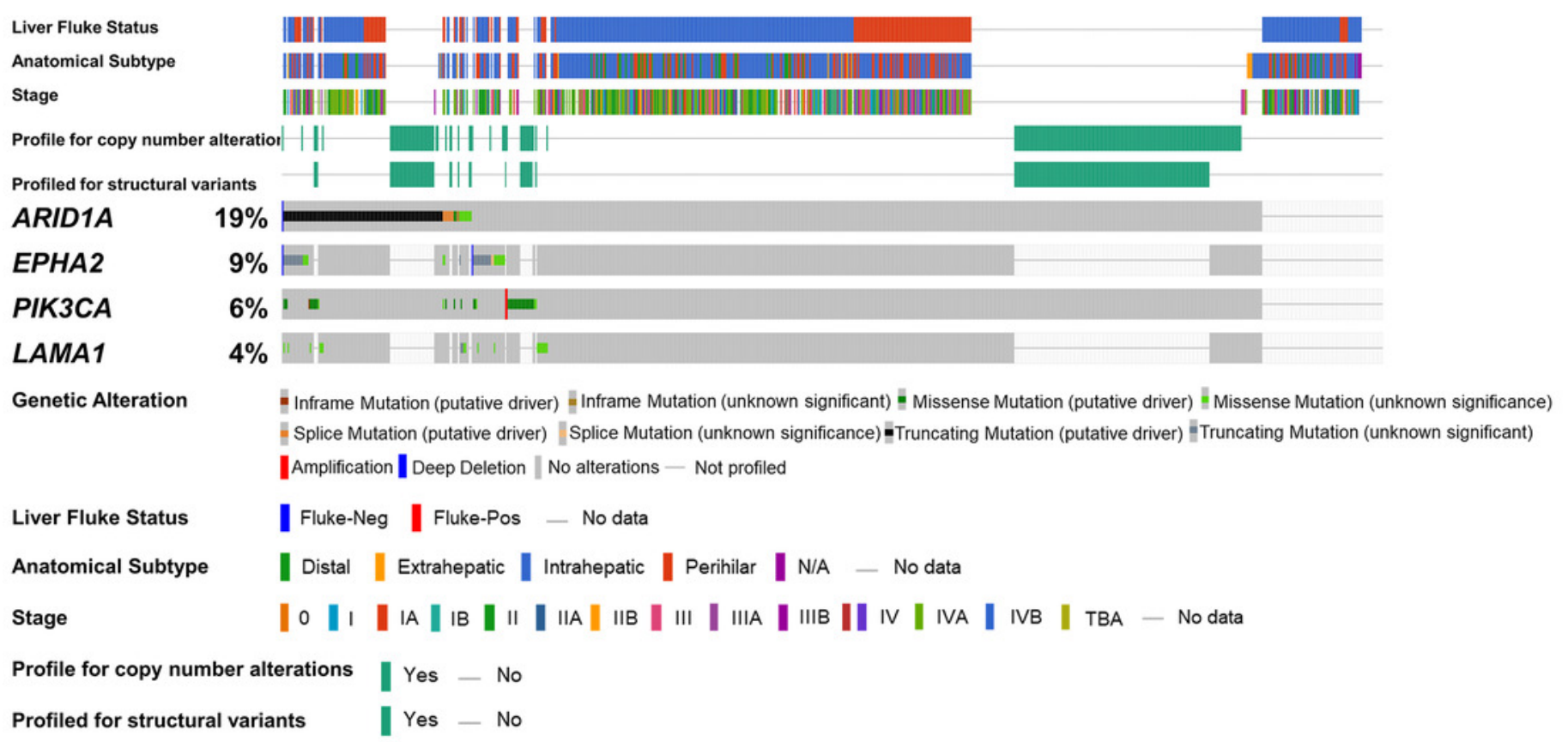


Figure 2

Genetic alterations of the $A R I D 1 A$ and its co-occurrence with alterations of EPHA2, PIK3CA and LAMA1.

(A) The Oncoplot shows a co-occurrence pattern of ARID1A mutations with EPHA2, PIK3CA and LAMA1 in CCA patients. (B) Type of ARID1A, EPHA2, PIK3CA, and LAMA1 mutations. (C) The co-alteration incidence for ARIDIA, EPHA2, PIK3CA, and LAMA1 mutations. adjusted * $p<0.05$, adjusted $* * p<0.01$, adjusted $* * * p<0.001$ was considered statistically significant (mut: mutant, wt: wild-type).

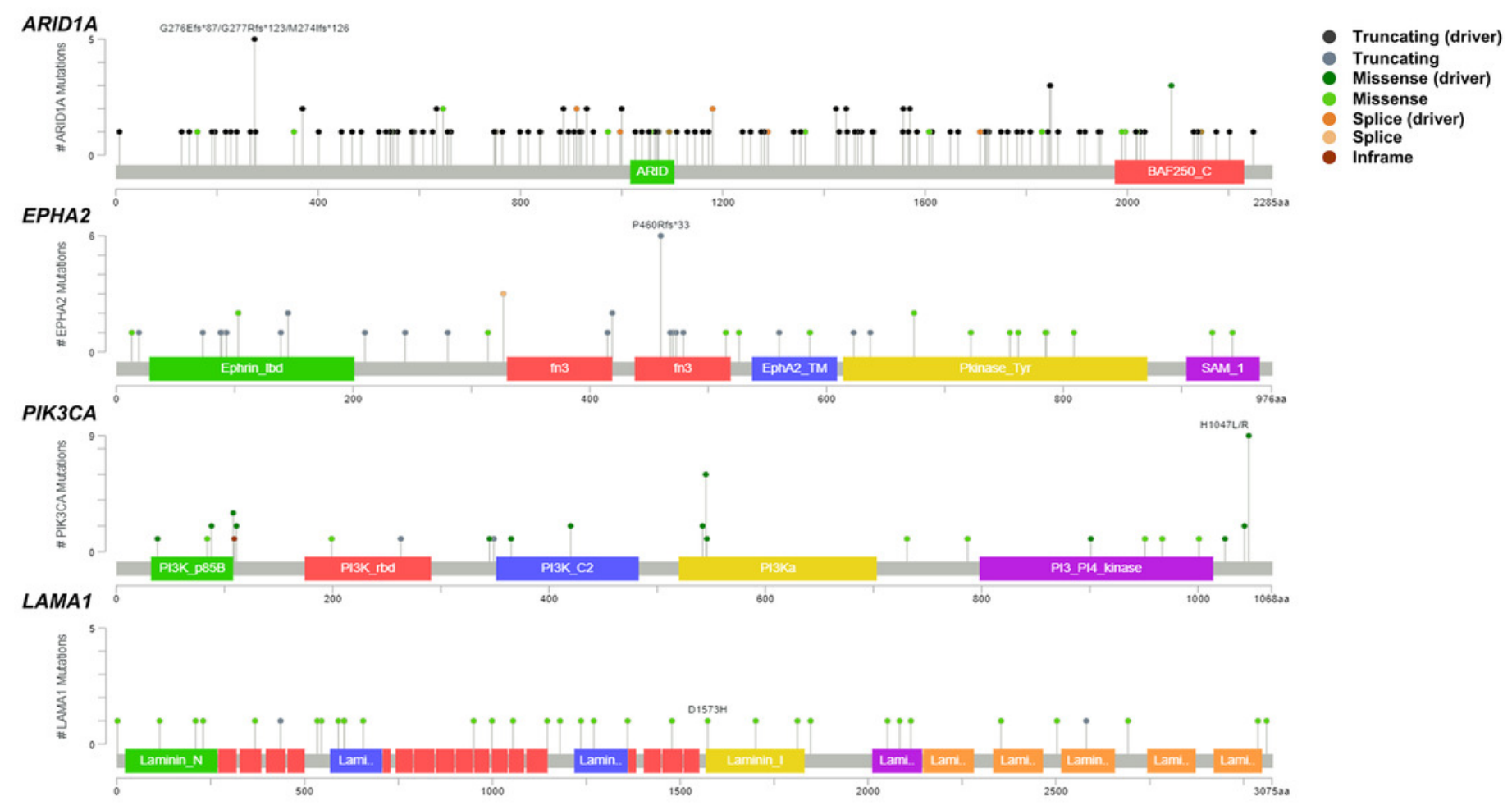


Figure 3

The prognostic value of $A R I D 1 A$ mutations and co-existent mutations with EPHA2, PIK3CA, and LAMA1.

The Kaplan-Meier survival analysis of overall survival in four selected studies cohort. Data were retrieved from the $\mathrm{cBioPortal}$ database. $* p<0.05,{ }^{* *} p<0.01, * * * p<0.001$ was considered statistically significant.

A
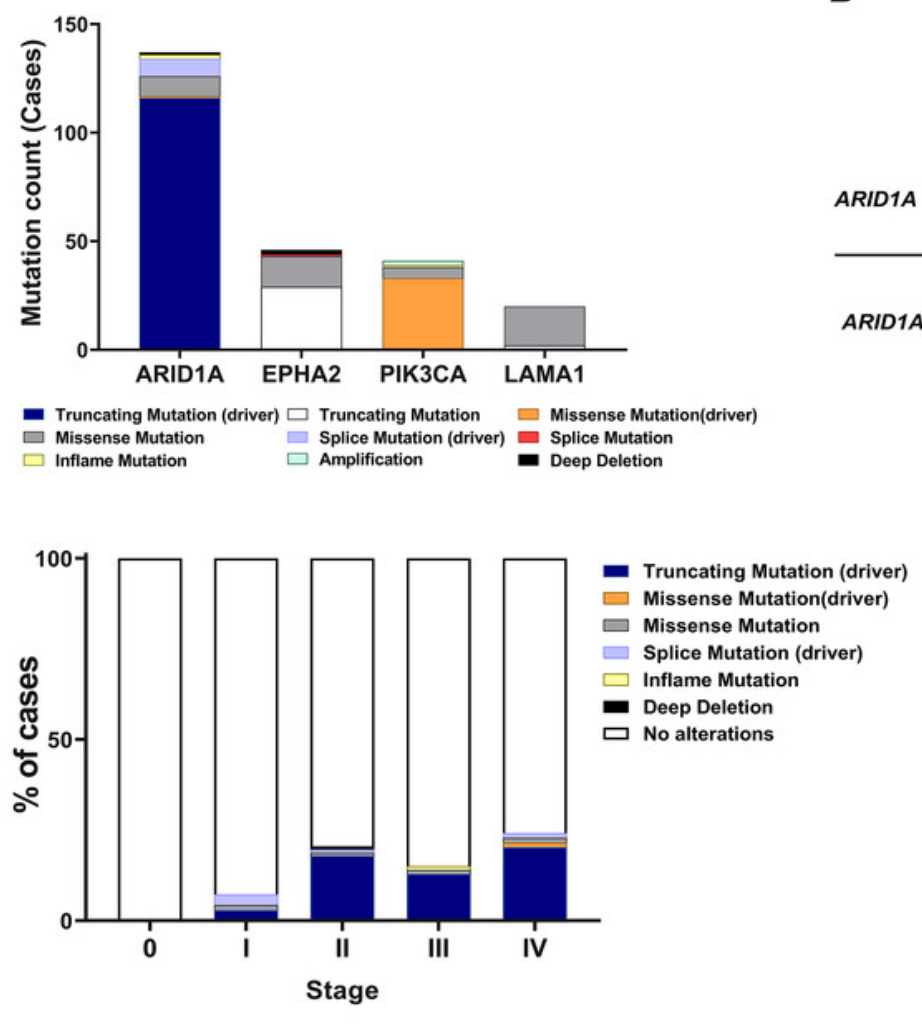

C

B

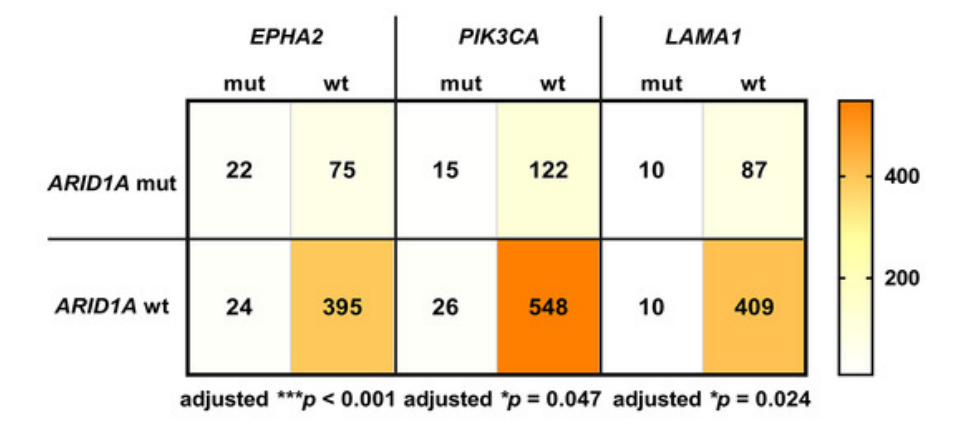

adjusted ${ }^{* * *} p<0.001$ adjusted ${ }^{*} p=0.047$ adjusted ${ }^{*} p=0.024$ 
Figure 4

Loss of ARID1A expression leads to increased sensitivity towards MK-2206 in ARID1Adeficient CCA cell lines.

(A) Western blot for the screening of ARID1A expression in five CCA cell lines. (B) ARID1Adepleted CCA cell lines (KKU-452 and KKU-055) were more sensitive to the treatment with MK-2206 when compared to KKU-213A and KKU-100 cells. Cell viability was measured by a MTT assay after $24 \mathrm{~h}$ of treatment. $* p=0.042,{ }^{*} p p<0.01$, pairwise comparisons.
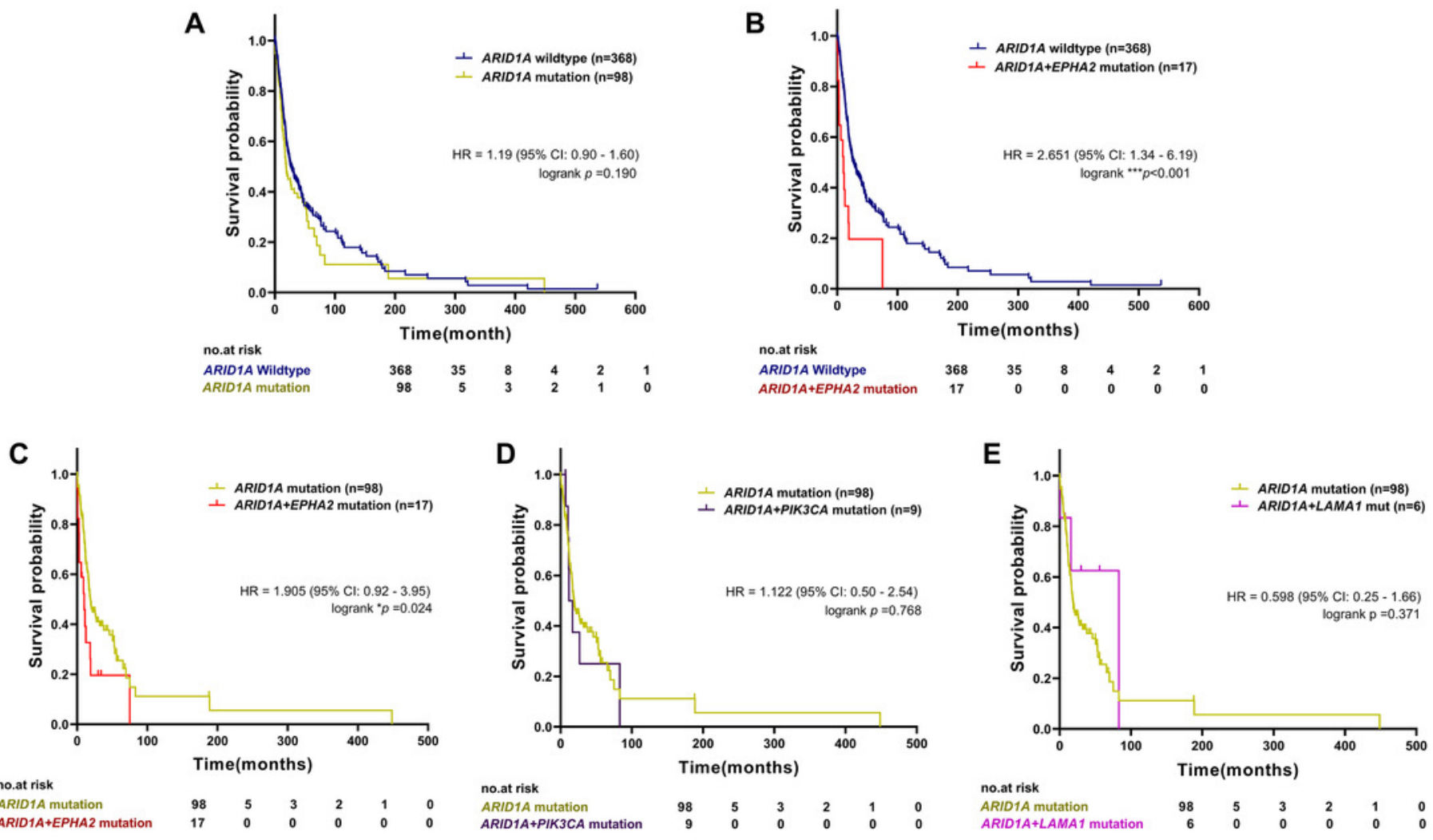
Figure 5

ARID1A-knockdown CCA cell lines show increased sensitivity towards MK-2206.

(A-B) ARID1A protein and mRNA expression were decreased in ARID1A-knockdown CCA cell lines (A: KKU-213A, B: HUCCT1) using a different shRNA sequence for ARIDIA (shARID1A\#1 and shARID1A\#2) compared to non-targeting shRNA control cells (shN). (C-D) The effect of MK-2206 (0-50 $\mu \mathrm{M})$ on cell viability in ARID1A-knockdown CCA cell lines (C: KKU-213A, D: HUCCT1). Cells were treated with 2.5-50 $\mu \mathrm{M}$ of MK-2206 for $24 \mathrm{~h}$ and cell viability was measured using MTT assay. (E-F) The IC50 values of ARID1A-knockdown CCA cell lines (E: KKU-213A, F: HUCCT1) decreased compared to the control (shN). ${ }^{*} p<0.05,{ }^{* *} p<0.01$, $* * * p<0.001$ was considered statistically significant.

A

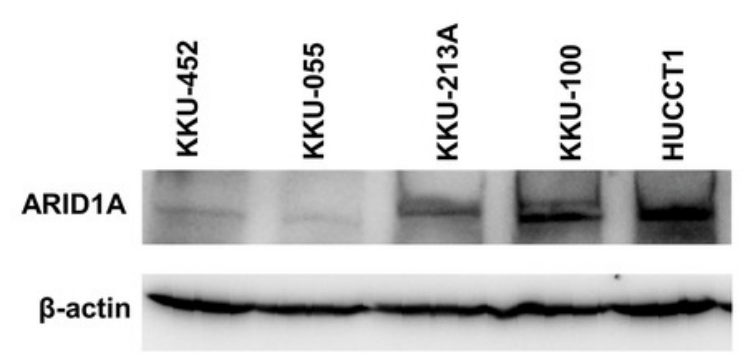

C

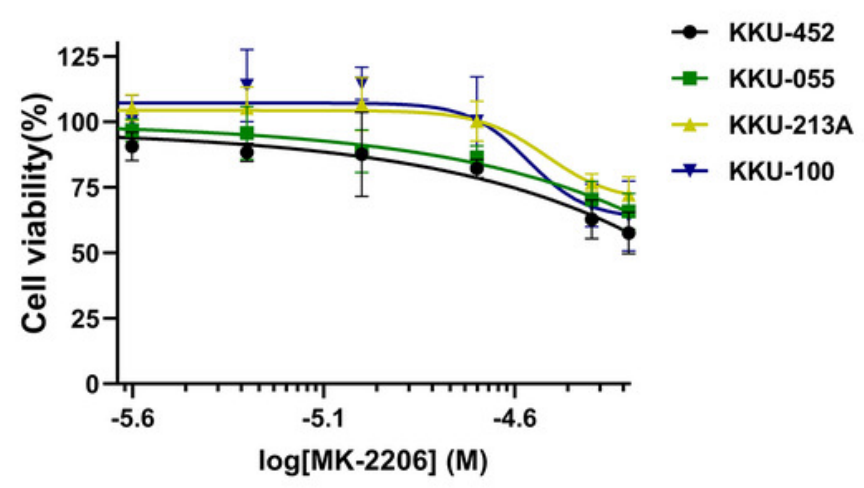

B

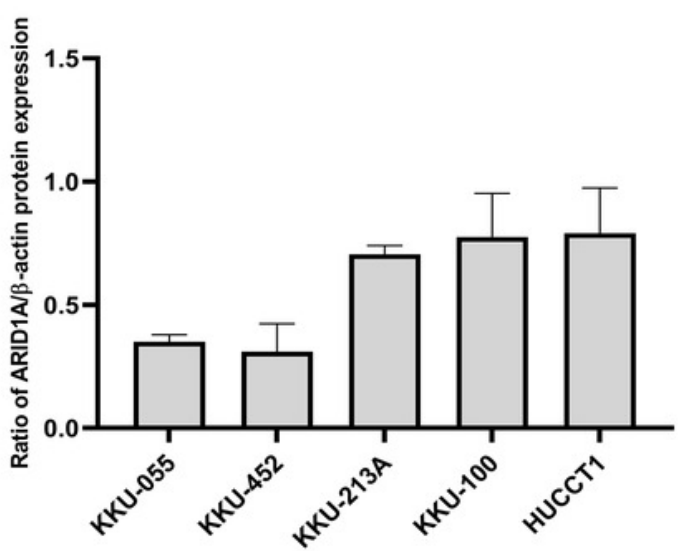

D

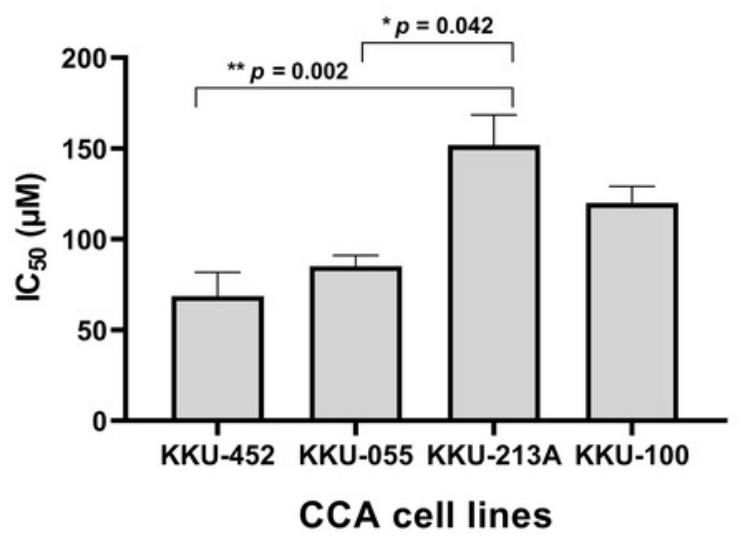


Figure 6

MK-2206 induces apoptosis in ARID1A-knockdown CCA cell lines.

(A) Flow cytometry shows that treatment with MK-2206 (24 h) led to increased apoptosis in ARID1A-knockdown KKU-213A cell lines (ShARID1A) as compared with non-targeted shRNA control cells (shN). (B) The number of apoptotic cells was expressed as $\%$ of total cell number. ${ }^{* *} p<0.01 ;$ unpaired t-test.
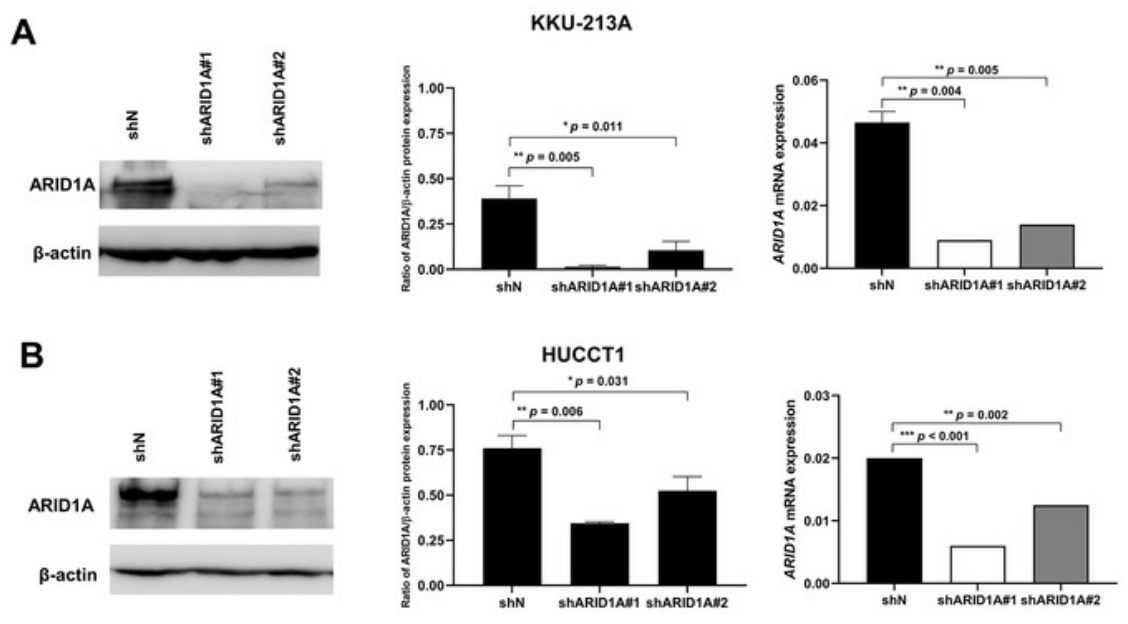

C

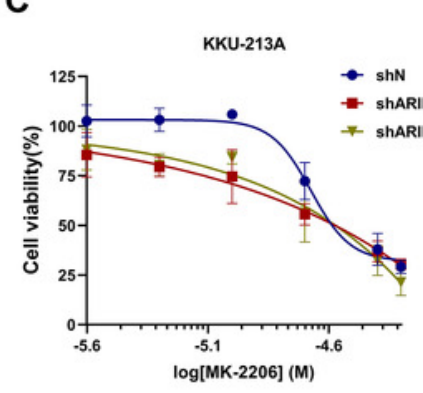

D

E
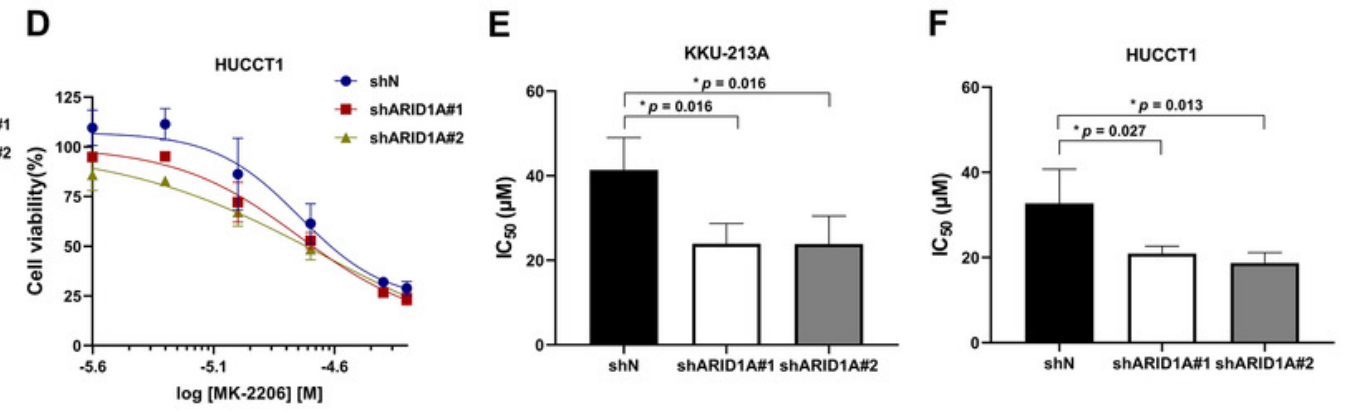


\section{Figure 7}

AKT inhibition induces apoptosis in ARID1A-knockdown CCA cell lines and decreases phosphorylation of AKT.

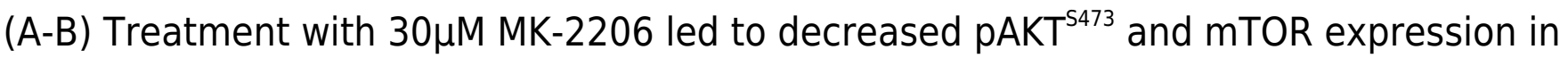
ARID1A-knockdown CCA cell lines (A; KKU-213A, B; HUCCT1) compared to non-targeted shRNA control cell (shN). (C) Densitometric quantification of the relative $p A K T^{5473} / A K T$ expression in CCA cell lines (ImageJ version 1.53a, NIH, USA). Relative pAKT ${ }^{5473} / A K T$ levels decreased in ARIDIA-knockdown CCA cell lines compared to non-targeted shRNA control cells (shN). (D) Densitometric quantification of the relative Bax/Bcl-2 expression in CCA cell lines. Relative Bax/Bcl-2 levels were increased in ARIDIA-knockdown CCA cell lines compared to non-targeted shRNA control cells (shN). Cells were treated with MK-2206 for 12 hours (12 h) or 24 hours ( $24 \mathrm{~h}$ ) and $0.3 \%$ DMSO was used as the control (Ctl). ${ }^{*} p<0.05$; unpaired t-test.

A

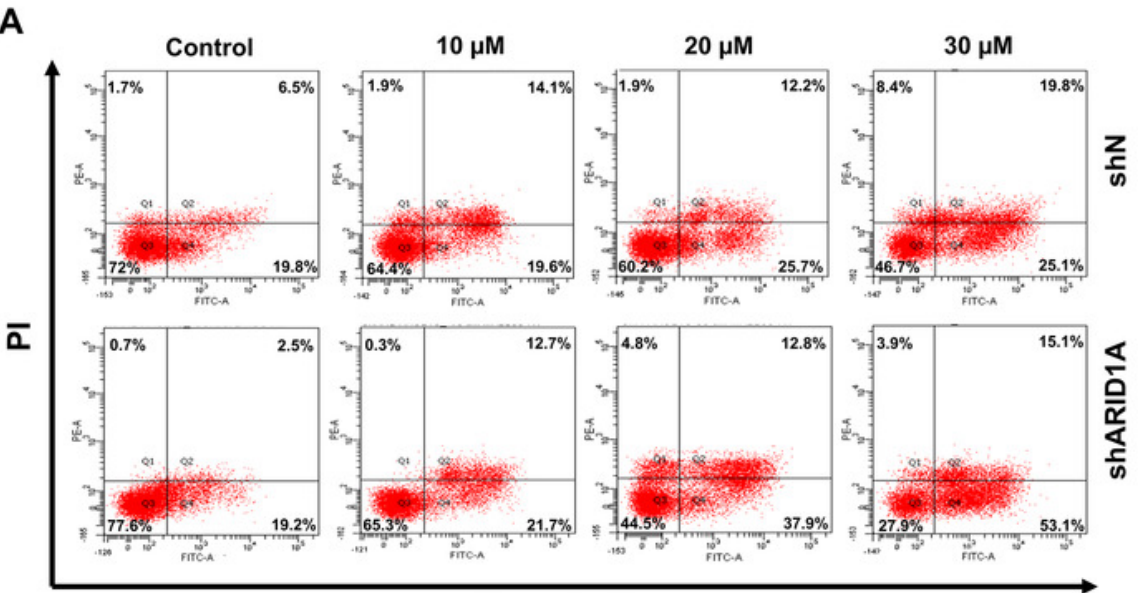

Annexin V
B

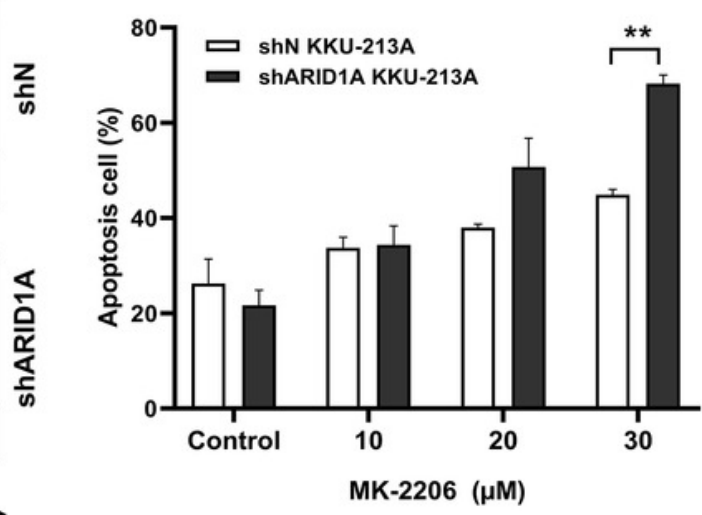




\section{Figure 8}

AKT inhibition decreases phosphorylation of AKT, mTOR and induces apoptosis in ARID1A-knockdown CCA cell lines.

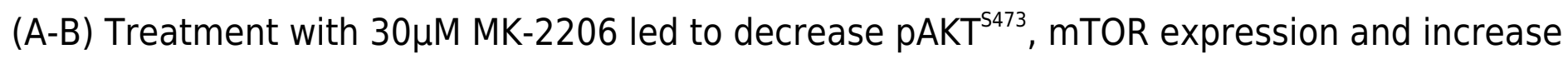
Bax/BCl-2 ratio in ARID1A-knockdown CCA cell lines (A; KKU-213A, B; HUCCT1) compared to non-targeted shRNA control cell (shN). (C) Decreased ratios of $\mathrm{PAKT}^{\mathrm{s473} / \mathrm{AKT}}$ in ARIDIAknockdown CCA cell lines were observed than that of non-targeted shRNA control cells (shN). (D) Decreased ratios of mTOR/ $\beta$-actin in ARIDIA-knockdown CCA cell lines were observed than that of non-targeted shRNA control cells (shN). Densitometric quantification of protein expression in CCA cell lines were obtained using ImageJ (version 1.53a, NIH, USA). Cells were treated with MK-2206 for 12 hours (12 h) or 24 hours ( $24 \mathrm{~h}$ ) and $0.3 \%$ DMSO was used as the control. 
A

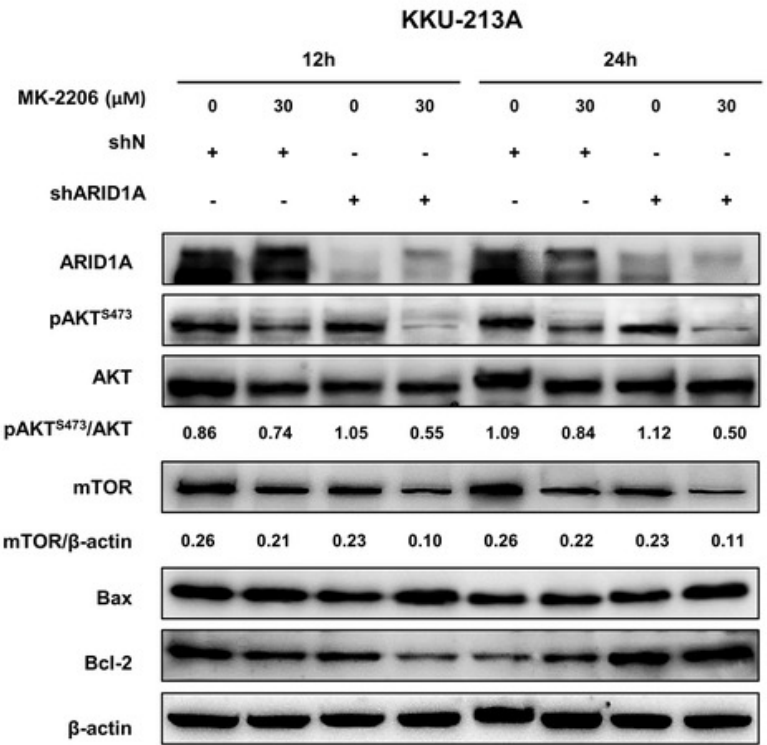

C
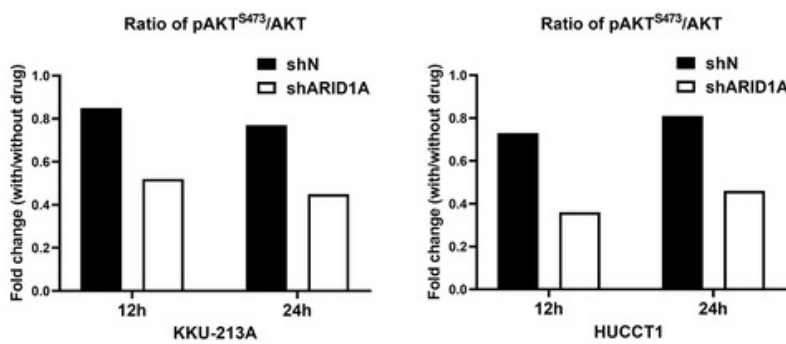

B

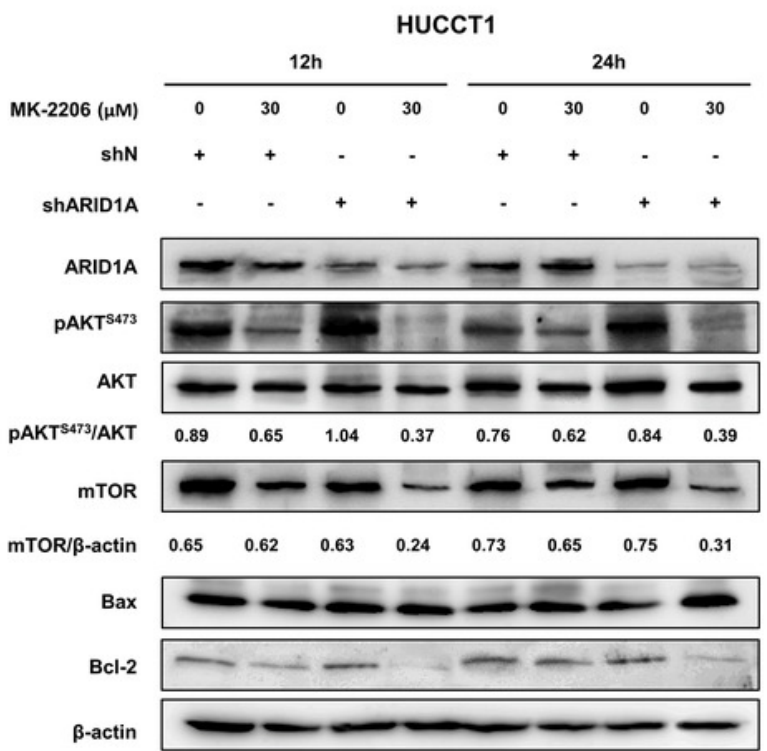

D
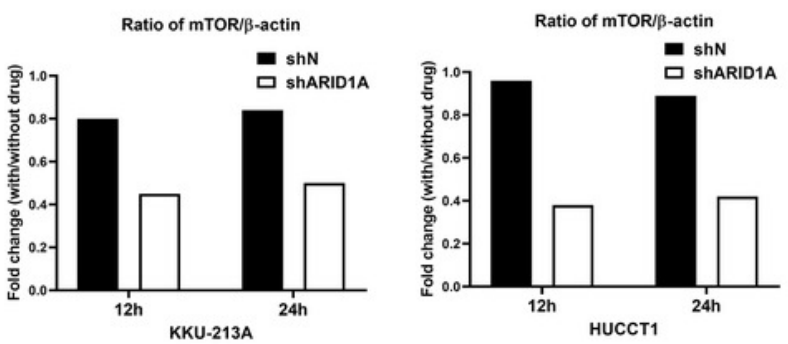